\title{
Penilaian Kemampuan Passing Sepak Bola Melalui Observasi Penilaian Pada Kegiatan Ekstrakurikuler Sepak Bola SD Negeri 107826 Pematang Sijonam Kecamatan Perbaungan Tahun Ajaran 2020/2021
}

\section{Teddy Pramadani ${ }^{1}$, Dewi Maya Sari ${ }^{2}$}

1,2 Sekolah Tinggi Olahraga dan Kesehatan Bina Guna, Indonesia

Jl. Aluminium Raya No. 77, Tanjung Mulia, Medan, Sumatera Utara

Email : Teddypra@gmail.com

\begin{abstract}
ABSTRAK
Penelitian ini merupakan penelitian kuantitatif deskriptif dengan satu variabel tanpa membuat perbandingan dan menghubungkan dengan variabel lainnya. Penelitian deskriptif dilakukan untuk menggambarkan gejala, fenomena atau peristiwa tertentu, tanpa pengujian hipotesis. Metode yang digunakan dalam penelitian ini adalah observasi penilaian yang dilakukan untuk mengetahui tingkat passing sepak bola. Populasi dalam penelitian ini yaitu seluruh siswa SD Negeri 107826 yang mengikuti kegiatan ekstrakurikuler sepak bola yang berjumlah 25 siswa. Jadi sampel penelitian ini adalah siswa SD Negeri 107826 Pematang Sijonam yang mengikuti kegiatan ekstrakurikuler sepak bola yang berjumlah 25 siswa, dengan menggunakan total sampling. Teknik pengumpulan data dalam penelitian ini menggunakan metode observasi dengan melengkapinya dengan format atau blangko pengamatan keterampilan passing sepakbola. Komponen-komponen dalam format atau blangko observasi penilaian adalah alat pengumpulan data. Teknik analisis data dalam penelitian ini menggunakan teknik analisis data deskriptif. Hasil analisis menunjukkan bahwa kemampuan passing sepak bola melalui observasi penilaian pada kegiatan ekstrakurikuler sepak bola SD Negeri 107826 Pematang Sijonam Kecamatan Perbaungan tahun ajaran 2020/2021, dalam kategori baik. Dari hasil perhitungan juga diketahui siswa yang masuk kategori "sangat baik" sebanyak 0 siswa (0\%), kategori "baik" sebanyak 14 siswa (56\%), kategori "cukup" sebanyak 9 siswa (36\%), kategori "kurang baik" sebanyak 0 siswa $(0 \%)$.
\end{abstract}

\section{Kata kunci: Kemampuan passing sepak bola}

\begin{abstract}
This research is a descriptive quantitative study with one variable without making comparisons and connecting with other variables. Descriptive research is conducted to describe specific symptoms, phenomena or events, without hypothetical testing. The method used in this study is the observation of assessments made to find out the level of football passing. The population in this study was all students of SD Negeri 107826 who participated in extracurricular football activities totaling 25 students. So the sample of this study is students of SD Negeri 107826 Pematang Sijonam who participated in extracurricular football activities totaling 25 students, using total sampling.

The data collection techniques in this study use observation methods by supplementing them with the format or blangko observation of football passing skills. Components in the format or blangko observation assessment is a data collection tool. The data analysis techniques in this study use descriptive data analysis techniques.
\end{abstract}


The results of the analysis showed that the ability to pass football through observation scoring in the extracurricular activities of SD Negeri 107826 Pematang Sijonam District Perbaungan school year 2020/2021, in the good category. From the calculation results are also known students who entered the category of "very good" as many as 0 students $(0 \%)$, the category "good" as many as 14 students (56\%), the category "enough" as many as 9 students (36\%), the category "less good" as much as 0 students $(0 \%)$.

\section{Keywords: Football passing ability}

\section{PENDAHULUAN}

Sepakbola memerlukan penguasaan teknik dasar, hal ini dikarenakan penguasaan teknik dasar bermain sepakbola merupakan modal utama untuk bermain sepakbola, dalam permainan sepakbola teknik dasar mutlak harus dikuasai oleh seorang pemain. Teknik dasar dalam sepakbola dibagi menjadi dua, yaitu teknik badan (teknik tanpa bola), meliputi: cara lari, cara melompat, gerak tipu badan dan teknik dasar dengan bola meliputi: kontrol bola, menendang bola, menyundul bola, merebut bola, lemparan ke dalam, menjaga gawang. Ada beberapa teknik dasar yang perlu dimiliki seorang pemain sepakbola adalah menendang (kicking), menghentikan (stoping), menggiring (dribbling), menyundul (heading), merampas (tackling), lemparan ke dalam (throw-in), dan menjaga gawang (goal keeping). Dalam permainan sepakbola hampir semua teknik tersebut digunakan selama pertandingan walaupun kadang-kadang teknik tanpa bola atau gerakan tanpa bola memberikan andil yang cukup besar untuk membantu penyerangan dan pertahanan.

Sepak bola termasuk kedalam salah satu materi yang diajarkan pada mata pelajaran pendidikan jasmani di SD Negeri 107826 Pematang Sijonam dan salah satu yang menjadi materi tersebut adalah passing. Dalam pembelajaran sepak bola khususnya dalam materi passing, kemampuan siswa masih rendah. Hal ini dikarenakan proses pembelajaran sepak bola kurang di tekankan pada siswa. Dalam arti siswa hanya sekedar tahu apa itu permainan sepak bola, tanpa ada penambahan informasi yang lebih mendalam tentang permainan sepak bola, bahkan pelatih jangan sekali memberikan materi permainan sepak bola khususnya teknik passing yang benar.

Passing tujuannya untuk memberikan atau mengoper bola kepada teman. Passing yang baik dan benar sangat dibutuhkan dalam bermain sepak bola, karena dengan menguasai teknik ini maka akan mempermudah teman untuk menerima bola. Untuk penguasaan passing, diperlukan penguasaan gerakan sehingga sasaran yang diinginkan tercapai. Masih banyak siswa yang melakukan passing dengan tendangan keras atau pun terlalu lemah, sehingga hasil yang didapat tidak sesuai arah yang diinginkan, sehingga saat mengumpan bola kepada teman sering terjadi kesalahan.

Permasalahan yang sering dihadapi oleh siswa adalah passing kurang akurat dan maksimal sehingga tidak tepat sasaran dan tidak terarah. Hal ini dapat dilihat pada saat siswa yang kurang memahami teknik dasar passing, seperti laju bola tidak sesuai dengan jarak passing, umpan tidak akurat, mengumpan padahal waktunya untuk menembak, perkenaan kaki tidak pada bagian dalam, perkenaan bola terlalu kebawah sehingga bola melambung, kaki tidak dikunci dan tidak mantap sehingga bola tidak keras, kaki tidak diayun tetapi hanya disentuhkan atau hanya disaruk saja, tidak memperhatikan arah operan sehingga tidak sampai pada

tujuan. 


\section{METODE PENELITIAN}

Sesuai dengan tujuan penelitian ini yaitu untuk mengetahui tingkat kemampuan passing sepak bola di SD Negeri 107826 Pematang Sijonam Kecamatan Perbaungan. Penelitian ini merupakan penelitian kuantitatif deskriptif dengan satu variabel tanpa membuat perbandingan dan menghubungkan dengan variabel lainnya. Penelitian deskriptif dilakukan untuk menggambarkan gejala, fenomena atau peristiwa tertentu, tanpa pengujian hipotesis. Metode yang digunakan dalam penelitian ini adalah observasi penilaian yang dilakukan untuk mengetahui tingkat passing sepak bola. Populasi dalam penelitian ini yaitu seluruh siswa SD Negeri 107826 yang mengikuti kegiatan ekstrakurikuler sepak bola yang berjumlah 25 siswa.

Tabel 1. Kisi-Kisi Penilaian Kemampuan Passing Sepak Bola

\begin{tabular}{|c|c|c|c|}
\hline No & Indikator & Deskriptor & No Butir \\
\hline 1 & Sikap awal & $\begin{array}{l}\text { a. Berdiri menghadap target } \\
\text { b. Letakkan kaki yang menahan } \\
\text { keseimbangan disamping bola } \\
\text { c. Arahkan kaki ke target } \\
\text { d. Kaki ditempatkan dalam posisi } \\
\text { menyamping } \\
\text { e. Fokus perhatian pada bola }\end{array}$ & $1,2,3,4,5$ \\
\hline 2 & Sikap Pelaksanaan & $\begin{array}{l}\text { a. Tubuh berada di atas bola } \\
\text { b. Lutut sedikit ditekuk } \\
\text { c. Ayunkan kaki yang akan } \\
\text { menendang ke depan } \\
\text { d. Pandangan melihat kesasaran yang } \\
\text { di tuju } \\
\text { e. Tendang bagian tengah bola } \\
\text { dengan bagian samping dalam kaki }\end{array}$ & $1,2,3,4,5$ \\
\hline 3 & Follow through & $\begin{array}{l}\text { a. Berat badan dipindah kedepan } \\
\text { b. Lanjutkan gerakan searah dengan } \\
\text { bola } \\
\text { c. Gerakan akhir berlangsung dengan } \\
\text { mulus } \\
\text { d. Kaki yang menendang mendarat } \\
\text { e. } \\
\text { e. Menjikit di depan kaki tumpu } \\
\text { eneimbangan }\end{array}$ & $1,2,3,4,5$ \\
\hline
\end{tabular}




\begin{tabular}{|c|l|l|c|}
\hline 4 & Hasil & a. Arah bola lurus ke depan & $1,2,3,4,5$ \\
& & b. Bola tepat sasaran & \\
& & c. Akurat dalam mengirimkan bola & \\
& & d. Bola mudah di terima & \\
\hline
\end{tabular}

Penilaian

Nilai 5 jika semua kriteria dilakukan secara benar

Nilai 4 jika hanya empat kriteria dilakukan secara benar

Nilai 3 jika hanya tiga kriteria dilakukan secara benar

Nilai 2 jika hanya dua kriteria dilakukan secara benar

Nilai 1 jika hanya satu kriteria dilakukan secara benar

\section{HASIL DAN PEMBAHASAN \\ Hasil}

Dari data hasil tes yang telah diperoleh tentang tingkat kemampuan passing sepak bola melalui observasi penilaian pada kegiatan ekstrakurikuler sepak bola SD Negeri 107826 Pematang Sijonam Kecamatan Perbaungan tahun ajaran 2020/2021 sebelumnya dianalisis dan diadakan verifikasi terlebih dahulu. Dalam penelitian ini peneliti mengukur kemampuan passing sepak bola melalui observasi penilaian pada kegiatan ekstrakurikuler sepak bola SD Negeri 107826 Pematang Sijonam Kecamatan Perbaungan tahun ajaran 2020/2021. Peneliti menghitung dengan media Microsoft Exel agar lebih cepat dan efisien. Data umum kemudian dijadikan sebagai acuan untuk menentukan kelas interval yang dapat disajikan dalam bentuk tabel distribusi frekuensi data berdasarkan hitungan. Secara keseluruhan, hasil penelitian diperoleh skor maksimum 16 dan skor minimum 7 dan rata-rata kemampuan passing sepak bola melalui observasi penilaian pada kegiatan ekstrakurikuler sepak bola SD Negeri 107826 Pematang Sijonam Kecamatan Perbaungan tahun ajaran 2020/2021 adalah 12.96, dibulatkan menjadi 13 dalam kategori baik, yang berada dalam kelas interval 13-16.

Tabel 2.

Distribusi Frekuensi Kelas Interval Kemampuan Passing Sepak Bola

\begin{tabular}{|c|l|c|c|}
\hline Interval & \multicolumn{1}{|c|}{ Kategori } & Frekuensi & Persentase \\
\hline $17-20$ & Sangat baik & 0 & 0 \\
\hline $13-16$ & Baik & 14 & 56 \\
\hline $9-12$ & Cukup & 9 & 36 \\
\hline $5-8$ & Kurang & 2 & 8 \\
\hline $1-4$ & Kurang baik & 0 & 0 \\
\hline \multicolumn{2}{|r|}{ Jumlah } & 25 & 100,00 \\
\hline
\end{tabular}




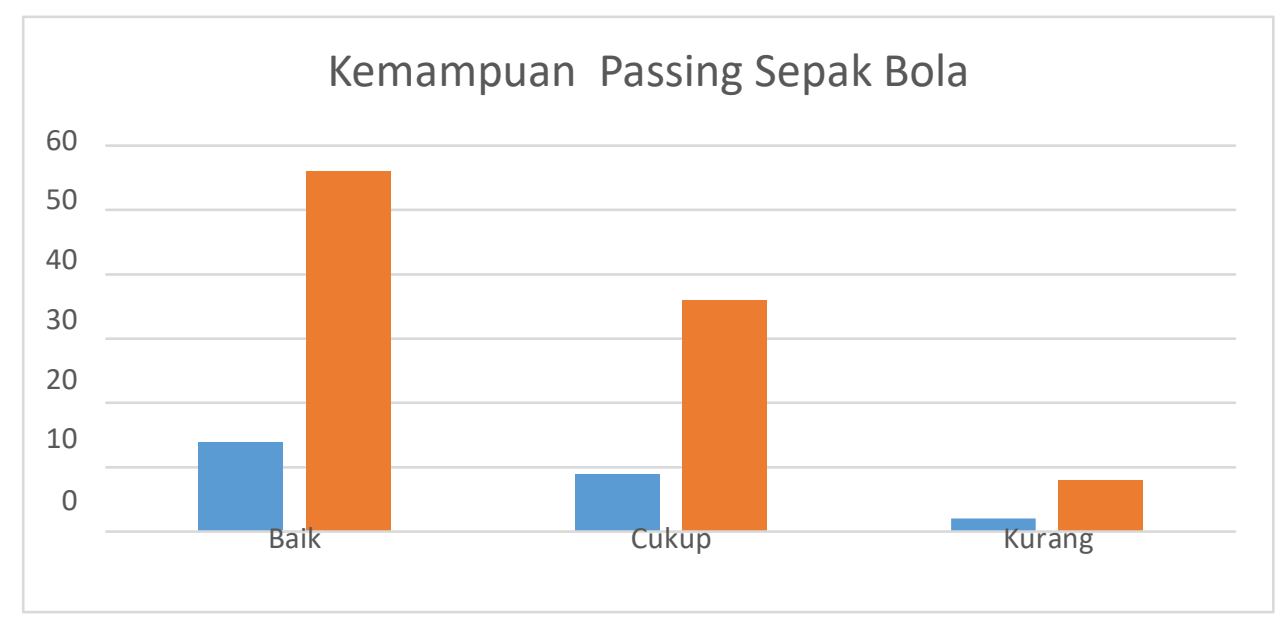

Diagram 1. Kemampuan Passing Sepak Bola Melalui Observasi Penilaian Pada Kegiatan Ekstrakurikuler Sepak Bola SD Negeri 107826 Pematang Sijonam Kecamatan Perbaungan Tahun Ajaran 2020/2021

Berdasarkan tabel 4.1 dan grafik 1 menunjukkan bahwa tingkat kemampuan passing sepak bola melalui observasi penilaian pada kegiatan ekstrakurikuler sepak bola SD Negeri 107826 Pematang Sijonam Kecamatan Perbaungan tahun ajaran 2020/2021, kemudian dikategorikan menjadi 5 kategori dengan rumus penjabaran diketahui siswa yang masuk kategori "sangat baik" sebanyak 0 siswa (0\%), kategori "baik" sebanyak 14 siswa (56\%), kategori "cukup" sebanyak 9 siswa (36\%), kategori "kurang baik" sebanyak 0 siswa (0\%),

\section{Pembahasan}

Penelitian ini bertujuan untuk mengetahui tingkat kemampuan passing sepak bola pada kegiatan ekstrakurikuler sepak bola di SD Negeri 107826 Pematang Sijonam. Berdasarkan hasil analisis menunjukkan bahwa tingkat kemampuan passing sepak bola pada kegiatan ekstrakurikuler sepak bola di SD Negeri 107826 Pematang Sijonam masuk dalam kategori "baik". Baiknya kemampun passing sepak bola dalam kategori baik, karena siswa sudah mendapat pembelajaran sepak bola secara menyeluruh, meliputi: teknik passing, controlling, dribbling, dan shooting. Pembelajaran hanya bermain telah dilandasi adanya penekanan terhadap teknik-teknik yang ada dalam olahraga sepak bola.

Permainan sepak bola dapat berlangsung lancar, teratur dan menarik apabila pemain menguasai unsur-unsur dalam permainan sepak bola salah satunya adalah penguasaan teknik dasar passing. Pada dasarnya ada beberapa teknik dasar yang harus dikuasai oleh pemain sepak bola seperti adalah dribbling, shooting dan passing. Namun dalam penelitian ini hanya dibatasi pada teknik dasar passing. Passing tujuannya untuk memberikan atau mengoper bola kepada teman. Passing yang baik dan benar sangat dibutuhkan dalam bermain sepak bola, karena dengan menguasai teknik ini maka akan mempermudah teman untuk menerima bola. Untuk penguasaan passing, diperlukan penguasaan gerakan sehingga sasaran yang diinginkan tercapai. Masih banyak siswa yang melakukan passing dengan 
tendangan keras atau pun terlalu lemah, sehingga hasil yang didapat tidak sesuai arah yang diinginkan, sehingga saat mengumpan bola kepada teman sering terjadi kesalahan.

Pada usia SMP 12 tahun - 16 tahun laki-laki telah memasuki tahap pengenalan teknik lanjutan untuk mereka yang telah memperoleh kemampuan teknik di lingkungan yang kompleks dan pada posisi yang spesifik. Untuk dapat bermain sepak bola dengan baik seorang pemain harus dibekali dengan skill/teknik dasar yang baik, tidak hanya sekedar bisa menendang bola tapi juga diperlukan keahlian dalam menguasai atau mengontrol bola. Sehingga kemampuan teknik dasar passing bermain sepak bola sangat dibutuhkan sekali dalam permainan atau pertandingan sepak bola. Dengan demikian tes kemampuan passing sepak bola sangat diperlukan untuk mengetahui seberapa besar kemampuan passing dalam bermain sepak bola yang dimiliki oleh setiap pemain. Berdasarkan hasil observasi tingkat kemampuan passing sepak bola pada kegiatan ekstrakurikuler sepak bola di SD Negeri 107826 Pematang Sijonam diketahui siswa yang masuk kategori "sangat baik" sebanyak 0 siswa (0\%), kategori "baik" sebanyak 14 siswa (56\%), kategori "cukup" sebanyak 9 siswa (36\%), kategori "kurang baik" sebanyak 0 siswa (0\%),

Dari hasil observasi ini semua peserta selain dituntut untuk melakukan teknik passing dengan cepat juga dituntut untuk melakukannya dengan tepat sesuai tahapan yang tercantum dalam instrumen observasi. Terdapat 14 siswa yakni 56\% masuk dalam kategori baik. Hal tersebut dikarenakan beberapa faktor yang dapat mempengaruhi tingkat kemampuan passing dalam permainan sepak bola. Adapun faktor-faktor yang dapat mempengaruhi yakni: (1) tingkat kemampuan bermain sepak bola (passing) pada tiap peserta ekstrakurikuler, (2) latihan. Faktor yang penting dalam pencapaian prestasi sepak bola seseorang adalah penguasaan kemampuan bermain sepak bola yang dimiliki oleh pemain itu sendiri. Bentuk kemampun bermain sepak bola seperti; teknik dasar mengumpan (passing). Untuk dapat menguasai kemampuan passing dalam bermain sepak bola yang baik dibutuhkan latihan yang rutin dan disiplin. Latihan dapat dilakukan dimana saja di luar sekolah dengan memanfaatkan lapangan-lapangan yang ada. Dengan demikian hasil penelitian secara keseluruhan dapat disimpulkan bahwa, kemampuan passing sepak bola pada kegiatan ekstrakurikuler sepak bola di SD Negeri 107826 Pematang Sijonam dinyatakan baik sebanyak 14 siswa (56\%). Selanjutnya, hal ini dapat memberikan pertimbangan terhadap pelatih agar dapat lebih meningkatkan lagi kemampuan bermain sepak bola pada kegiatan ekstrakurikuler sepak bola di SD Negeri 107826 Pematang Sijonam melalui latihan yang rutin dan terprogram.

\section{KESIMPULAN}

Dari hasil penelitian dapat diambil kesimpulan bahwa kemampuan passing sepak bola melalui observasi penilaian pada kegiatan ekstrakurikuler sepak bola SD Negeri 107826 Pematang Sijonam Kecamatan Perbaungan tahun ajaran 2020/2021, dalam kategori baik. Dari hasil perhitungan juga diketahui siswa yang masuk kategori "sangat baik" sebanyak 0 siswa (0\%), kategori "baik" sebanyak 14 siswa (56\%), kategori "cukup" sebanyak 9 siswa (36\%), kategori "kurang baik" sebanyak 0 siswa (0\%).

\section{DAFTAR PUSTAKA}


Karo, A. A. P. K., Sari, I. E. P., Sihombing, H., \& Sari, L. P. (2020). Effect of playing methods on the Dribble Ability of the Football Game. Kinestetik: Jurnal Ilmiah Pendidikan Jasmani, $4(2), 158-163$.

Departemen Pendidikan dan Kebudayaan. 2004. Kamus Besar Bahasa Indonesia, Jakarta: Balai Pustaka

Departemen Pendidikan Nasional. 2008. Standar Kompetensi Pendidikan Jasmani. Jakarta Dumphy. 2007. Teknik Permainan BolaVoli. Bandung: Alfabeta.

Hastuti, Tri Ani. 2008. Kontribusi Ekstrakulikuler Bolabasket Terhadap Pembibitan Atlet dan Peningkatan Kesegaran Jasmani.Yogyakarta: FIK UNY

Eti Nurhayati. 2011. Psikologi Perkembangan. Jakarta: Rineka Cipta

Rohim Abdul. 2008. Bermain Sepak Bola. CV. Aneka Ilmu

Saputra, Yuda M. 2009. Pengembangan Kegiatan KO dan Ektrakulikuler. Jakarta

Sucipto, dkk. 2000. Sepakbola. Jakarta: Depdikbud Dirjen Dikti.

Sudijono, Anas. 2006. Pengantar Statistik Pendidikan. Jakarta: Grafindo Persada.

Sugiyono. 2009. Statistika untuk Penelitian. Bandung: Alfabeta.

Suharsimi Arikunto. 2006. Prosedur Penelitian. Jakarta: Rineka Cipta.

Soekatamsi. 2005. Teknik Dasar Bermain Sepak Bola. Surakarta : Tiga Serangkai.

Sukintaka. 2004. Teori Pendidikan Jasmani ; Filosofi Pembelajaran \& Masa Depan. Bandung: Nuansa Cendikia

Yunus, M. 2002. Olahraga Pilihan Bola Voli. Dekdibud.

Yusuf. 2011. Permainan Bola Voli. Bandung: Alfabeta. 